\title{
Comparison of pancreatic morphology and exocrine functional impairment in patients with chronic pancreatitis
}

Department of

Internal Medicine and Gastroenterology T Bozkurt U Braun

$S$ Leferink

G Lux

and Department of Radiology

G Gilly

Community and

Academic Teaching

Hospital of the

University of Cologne,

Solingen, Germany

Correspondence to: Priv Doz Dr med T Bozkurt, Medizinische Klinik I, Städtisches Krankenhaus, Gotinstraße 1, D-42

Accepted for publication 29 November 1993

\begin{abstract}
A comparative analysis of pancreatic morphology and exocrine function was performed prospectively in 48 patients. All patients had transabdominal ultrasound, computed tomography, endoscopic retrograde pancreatography, and $a$ secretin-caerulein test. Classification of ultrasound, computed tomography, and pancreatogram findings was based on the Cambridge classification. In 10 patients, no pancreatic duct changes were detected on pancreatography. Equivocal (Cambridge I), mild to moderate (Cambridge II), and considerable ductal changes (Cambridge III) were found in 10, 12, and 16 patients, respectively. Computed tomography and ultrasound changes were found to correlate in $40-50 \%, 67 \%$, and $94-100 \%$ of patients with Cambridge $I$, II, and III abnormal duct morphology, respectively. In patients with a normal pancreatogram, no patient had a functional impairment. Seventy per cent of the patients with equivocal pancreatic duct changes had dissociated, and $30 \%$ global, pancreatic insufficiency, while $50 \%$ of those with mild to moderate abnormal duct morphology manifested dissociated, and $50 \%$ global, functional impairment. All patients with considerable pancreatic duct changes had global pancreatic insufficiency. The results of this study confirm that normal endoscopic retrograde pancreatographic findings and Cambridge III ductal changes on endoscopic retrograde pancreatography correlate extremely well with normal pancreatic function and advanced functional insufficiency, respectively. As diagnostic tools, ultrasound and computed tomography are as sensitive as pancreatography only in chronic pancreatitis with considerable morphological changes. (Gut 1994; 35: 1132-1136)
\end{abstract}

Endoscopic retrograde pancreatography (ERP), ultrasound, and computed tomography are complementary diagnostic means in the evaluation of disease severity in patients with chronic pancreatitis. ${ }^{12}$ Additional pancreatic function tests are usually necessary, however, to establish the degree of exocrine insufficiency, which is an important prognostic factor. ${ }^{12}$ As the evaluation of pancreatic function using direct or tubeless tests is a technique with a number of method related problems, it is necessary to find out if the degree of exocrine pancreatic insufficiency and morphological findings correlate, and if function tests are not required in some groups of patients with chronic pancreatitis. In general, a correlation has been shown between functional impairment and morphological changes in chronic pancreatitis by a number of previous studies most of which, however, did not take the severity grade of the disease into consideration. ${ }^{3-12}$ The main purpose of this study was to investigate prospectively the usefulness of the morphological changes in chronic pancreatitis compared with differing degrees of functional impairment measured by the secretin-caerulein test with the aim of identifying a possible correlation.

\section{Patients and methods}

A group of patients with suspected or proved chronic pancreatitis but not clinical or biochemical evidence of acute pancreatitis was investigated to clarify recurrent epigastric pain or weight loss, or both. None of the patients had previous history of necrotising pancreatitis. After admission to the department, all patients had transabdominal ultrasound and computed tomography examinations of the pancreas, as well as ERP and secretincaerulein test. Only patients with a technically successful secretin-caerulein test and pancreatograms with adequate demonstration of the pancreatic duct system were included in the study. The group contained 48 patients ( 39 males and 9 females) with an average age of 47 (range 23-79) years. The primary grading was based on the morphological changes seen in the pancreatogram. The results of all other imaging techniques and the secretin-caerulein test were compared with the ERP findings.

Transabdominal ultrasound of the pancreas was performed by an experienced examiner using a real time scanner - Picker LSC 7000 or Picker CS $192 \quad(3 \cdot 5-/ 5 \cdot 0-\mathrm{MHz}$ convex transducer) - as the first imaging procedure of the diagnostic investigation. Abdominal computed tomography was done using Siemens Somatom plus and Siemens Somatom $\mathrm{HiQ}-\mathrm{S}$ with a $5 \mathrm{~mm}$ layer thickness. Scans were reviewed by two experienced radiologists who were blinded to the ultrasound findings. A revised Cambridge classification of chronic pancreatitis was used for the grading of ultrasound findings and computed tomography changes (Table 1). ${ }^{13}$

ERP was carried out using an Olympus JF 1 T10 oder JF 1T20 fibrescope using the 
TABLE I Revised Cambridge classification of chronic pancreatitis ${ }^{13}$

\begin{tabular}{|c|c|c|c|c|}
\hline & & $E R P$ & & Ultrasound and computed tomography \\
\hline Normal & & \multicolumn{3}{|c|}{ Visualisation of the whole gland without abnormal features } \\
\hline Equivocal & (Cambridge I) & $\begin{array}{l}\text { Fewer than three } \\
\text { abnormal branches }\end{array}$ & one sign only & \multirow{2}{*}{$\begin{array}{l}\text { Main duct enlarged (less than } 4 \mathrm{~mm} \text { ) } \\
\text { Gland enlarged (up to twice normal) } \\
\text { Cavities (less than } 10 \mathrm{~mm} \text { ) } \\
\text { Irregular ducts } \\
\text { Focal reduction in parenchymal echogenicity } \\
\text { Echogenic foci in parenchyma } \\
\text { Increased or irregular echogenicity of wall of main } \\
\text { duct } \\
\text { Irregular contour to gland, particularly focal } \\
\text { enlargements }\end{array}$} \\
\hline $\begin{array}{l}\text { Mild } \\
\text { Moderate }\end{array}$ & (Cambridge II) & $\begin{array}{l}\text { More than three } \\
\text { abnormal branches } \\
\text { Abnormal main duct } \\
\text { and branches }\end{array}$ & $\begin{array}{l}\text { two or more } \\
\text { signs }\end{array}$ & \\
\hline Considerable & (Cambridge III) & \multicolumn{2}{|c|}{$\begin{array}{l}\text { As above with one or more of: } \\
\text { Large cavities (greater than } 10 \mathrm{~mm} \text { ) } \\
\text { Intraductal calculi } \\
\text { Ductal obstruction with stricture } \\
\text { Gross irregularity of main pancreatic duct }\end{array}$} & $\begin{array}{l}\text { Large cavities (greater than } 10 \mathrm{~mm} \text { ) } \\
\text { Calculi } \\
\text { Ductal obstruction (greater than } 4 \mathrm{~mm} \text { ) } \\
\text { Major ductal irregularity } \\
\text { Gross enlargements (greater than } 4 \mathrm{~mm} \text { ) } \\
\text { Contiguous organ invasion }\end{array}$ \\
\hline
\end{tabular}

accepted technique. Written informed consent was obtained from each patient. $x$ Rays were taken in the supine position and, if necessary, in the right or left oblique positions. In all patients with pancreas divisum, the pancreatic duct system was visualised through the major and accessory papillae. The pancreatograms were reviewed independently by two gastroenterologists, each of whom had performed at least $1000 \mathrm{ERCPs}$, and a single radiologist, all three blinded to the ultrasound and computed tomography results. The classification of pancreatogram findings was also based on the revised Cambridge terminology (Table 1). ${ }^{13}$ In accordance with morphological changes of the duct system, the severity of chronic pancreatitis was graded into three types such as equivocal (Cambridge I), mild to moderate (Cambridge II), and considerable (Cambridge III) (Table 1).

After an overnight fast, the secretincaerulein test was performed as the final diagnostic procedure according to current standardisation. A double lumen tube was placed under fluoroscopic guidance with its tip at the ligament of Treitz. A bolus injection of synthetic secretin (1 CU/kg body weight (bw), Sekretolin Diagnosticum, Hoechst AG, Frankfurt, Germany) was given during the first 60 minutes to estimate volume secretion and bicarbonate output. In the period from 60 to 120 minutes, coinfusion of secretin (CU/kg/h bw) and caerulein (25 ng/kg/h bw, Takus, Farmitalia Carlo Erba $\mathrm{GmbH}$, Freiburg, Germany) was applied to measure volume secretion and enzyme outputs. Enzyme activities of amylase and lipase as well as concentrations of bicarbonate were measured using current methods and substrates. ${ }^{14-16}$ Normal values for volume secretion ( $>300 \mathrm{ml} / \mathrm{h}$, range $302-686 \mathrm{ml} / \mathrm{h}$ ), bicarbonate $(>30 \mathrm{mmol} / \mathrm{h}$, range $31-72$ $\mathrm{mmol} / \mathrm{h}$ ), and enzyme outputs (amylase:

TABLE II ERP findings in patients with chronic pancreatitis

\begin{tabular}{llr}
\hline Cambridge classification & Morphological changes & $(n)$ \\
\hline Cambridge I $(\mathrm{n}=10)$ & Fewer than three abnormal branches & 10 \\
Cambridge II $(\mathrm{n}=12)$ & More than three abnormal branches & 2 \\
Cambridge III $(\mathrm{n}=16)$ & Abnormal main duct and branches & 10 \\
& Abnormal main duct and branches & 10 \\
& Ductal obstruction with stricture & 8 \\
& Intraductal calculi & 7 \\
& Gross irregularity of main duct & 7 \\
& Large cavities & 4 \\
\hline
\end{tabular}

$>5000 \mathrm{IU} / \mathrm{h}$, range 5024-11680 IU/h, lipase: $>100000 \mathrm{IU} / \mathrm{h}$, range $100676-287$ $542 \mathrm{IU} / \mathrm{h}$ ) have been previously reported in 40 healthy subjects in our laboratory. Dissociated pancreatic insufficiency was defined as an impairment of function if not more than two parameters were abnormal in the secretincaerulein test. In the case of three to four abnormal parameters, pancreatic insufficiency was considered to be global.

All results were expressed as means (SEM). Statistical analyses were carried out using the Fisher's exact probability test. Significance was set at the $5 \%$ value.

\section{Results}

Chronic alcohol abuse was the cause of chronic pancreatitis in $29(76 \%)$ patients, of whom four had a pancreas divisum. No aetiological cause was apparent in the remaining nine (24\%) patients. In patients with normal pancreatic duct morphology, six (60\%) were known to be chronic alcohol abusers. Among the patients as a whole, the diagnostic investigation was necessary in $30(63 \%)$ patients because of recurrent epigastric pain and weight loss. Twelve $(25 \%)$ patients suffered only from epigastric pain, and six $(12 \%)$ only from rapid weight loss. In patients without pancreatic duct changes, the mean body weight was $6.3(19.9) \%$ higher than normal in accordance with Broca's formula. Among the patients with Cambridge I, II, and III morphology as shown by ERP, the mean body weight was $1.0(3.7) \%, 3.3(9.4) \%$, and $4 \cdot 7(11 \cdot 3) \%$ lower than normal, respectively. Diabetes mellitus was found in $30 \%(n=3)$ $42 \%(n=5)$, and $56 \%(n=9)$ of patients with Cambridge I, II, and III morphological changes, respectively. Of the patients with normal pancreatic duct morphology, none was diabetic.

In 10 of 48 patients, ERP showed no pancreatic duct changes. Equivocal (Cambridge I), mild to moderate (Cambridge II), and considerable ductal changes (Cambridge III) were found in 10,12 , and 16 patients, respectively (Table II). Ultrasound and computed tomography showed morphological changes in 38 and 37 cases, respectively. In patients with normal pancreatograms, computed tomography and ultrasound suggested equivocal changes in $40 \%$ and $50 \%$ of the cases, respec- 
TABLE III Ultrasound and computed tomography findings (n) in patients with normal pancreatic duct morphology and chronic pancreatitis shown by ERP

\begin{tabular}{llcc}
\hline \multirow{2}{*}{ Cambridge classification } & & \\
\hline Normal $(\mathrm{n}=10)$ & Morphological changes & $\begin{array}{c}\text { Computed } \\
\text { tomography }\end{array}$ \\
& Normal & 5 & 6 \\
& Focal reduction in parenchymal echogenicity & 3 & 2 \\
& Irregular contour to gland & 2 & 2 \\
Cambridge I $(\mathrm{n}=10)$ & Normal & 5 \\
& Focal reduction in parenchymal echogenicity & 3 & 3 \\
& Irregular contour to gland & 2 & 2 \\
& Focal reduction in parenchymal echogenicity & 12 & 12 \\
Cambridge II $(\mathrm{n}=12)$ & 4 & 6 \\
& Irregular contour to gland & 4 & 2 \\
& Echogenic foci in parenchyma & 2 & 2 \\
& Gland enlarged & 16 \\
& Focal reduction in parechymal echogenicity & 16 & 16 \\
& Irregular contour to gland & 12 & 11 \\
& Echogenic foci in parenchyma & 7 & 6 \\
& Gland enlarged & 11 & 12 \\
& Calculi & 5 & 4 \\
& Ductal obstruction (greater than 4 mm) & 7 & 4 \\
& Large cavities (greater than 10 mm) & 6 & 4 \\
& Major duct irregularity & 4 & 2 \\
\hline
\end{tabular}

TABLE IV Distribution of abnormal parameters ( $n$ ) measured by secretin-caerulein test

\begin{tabular}{llllllc}
\hline \multicolumn{2}{l}{ Cambridge classification } & Volume & $\mathrm{HCO}_{3}$ & Amylase & Lipase \\
\hline Normal & & $(\mathrm{n}=10)$ & 0 & 0 & 0 & 0 \\
Cambridge I & D & $(\mathrm{n}=7)$ & 0 & 4 & 3 & 7 \\
Cambridge II & G & $(\mathrm{n}=3)$ & 3 & 3 & 3 & 3 \\
\multirow{2}{*}{ Cambridge III } & G & $(\mathrm{n}=6)$ & 0 & 4 & 2 & 6 \\
& G & $(\mathrm{n}=16)$ & 16 & 16 & 6 & 16 \\
\hline
\end{tabular}

$\mathrm{D}=$ Dissociated insufficiency; $\mathrm{G}=$ global insufficincy.

tively (Table III). On the other hand, in $50 \%$ of patients with pancreatograms of Cambridge I findings, no abnormal changes were shown using computed tomography and ultrasound (Table III). Eight (67\%) patients with Cambridge II changes on pancreatograms, had two or more abnormal signs on ultrasound and computed tomography, while four $(23 \%)$ subjects were classified as Cambridge I on the basis of ultrasound and computed tomography findings. In all patients with Cambridge III findings shown by ERP, considerable morphological changes were confirmed in $100 \%$ and $94 \%$ of cases using ultrasound and computed tomography, respectively (Table III). In none of the groups were any significant discrepancies found between ultrasound and computed tomography findings.

Overall, 38 of 48 patients had an impairment of pancreatic function as shown by
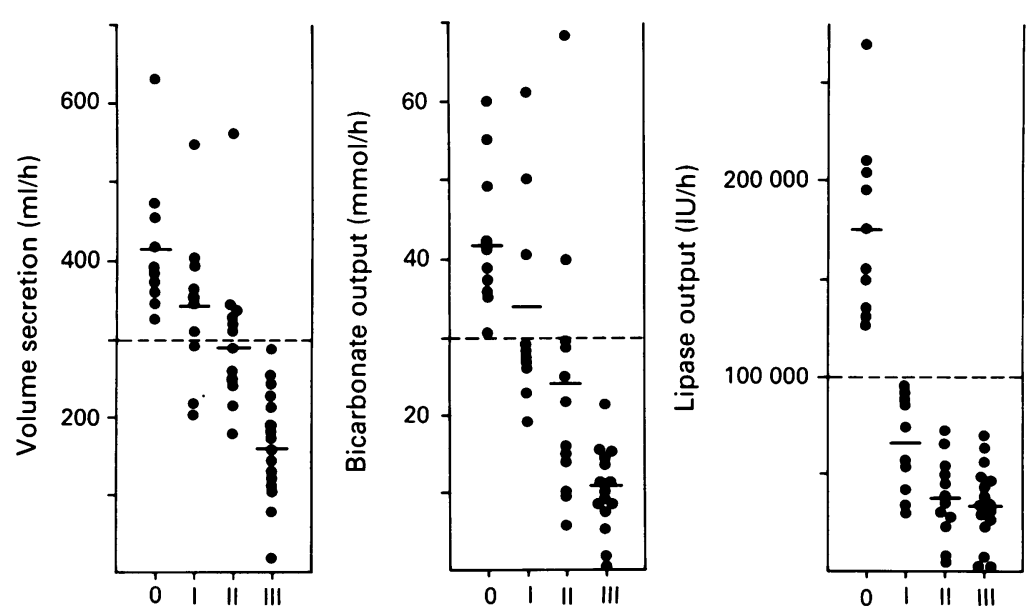

Cambridge classification

Distribution of individual parameters in patients with normal pancreatograms (0) and chronic pancreatitis (I-III). the secretin-caerulein test. In 13 patients a dissociated functional impairment was found, while 25 patients were shown to have global insufficiency. Among patients with normal ERP, none had pancreatic functional impairment (Table IV, Figure). Patients with equivocal pancreatic duct changes had dissociated and global pancreatic insufficiency in $70 \%$ and $30 \%$ of the cases, respectively. In patients with mild to moderate abnormal duct morphology $50 \%$ had dissociated, and $50 \%$ global functional impairment. Considerable pancreatic duct findings were always accompanied by global pancreatic insufficiency (Table IV, Figure). Among patients with pancreas divisum, ERP showed no further duct changes in one, who also had normal pancreatic function. Three patients with pancreas divisum had equivocal abnormal findings on ERP, accompanied by dissociated impairment of the pancreatic function.

In patients with dissociated pancreatic insufficiency, lipase, bicarbonate, amylase outputs, and volume secretion were abnormal in $100 \%, 62 \%, 38 \%$, and $0 \%$ of the cases, respectively (Table IV). In comparison with normal pancreatic function, the mean volume secretion, bicarbonate, and amylase outputs in Cambridge I type pancreatitis were reduced by $17 \%, 19 \%$, and $27 \%$, respectively, while lipase output was impaired by $64 \%$ (Table V). In Cambridge II patients, a reduction in mean volume secretion of $30 \%$ was found. Bicarbonate, amylase, and lipase outputs were reduced by $43 \%, 55 \%$, and $78 \%$, respectively (Table V). In the case of considerable chronic pancreatitis, there was a decrease in mean volume secretion, amylase, and bicarbonate outputs of $62 \%, 72 \%$, and $74 \%$, respectively, while lipase output was reduced by $81 \%$ (Table V).

Among the four parameters examined, lipase output was found to be abnormal in all patients with dissociated or global functional impairment, and could be used to distinguish between normal and abnormal duct morphology without exception. A significant differentiation between equivocal and mild to moderate pancreatitis was possible on the basis of mean lipase output, while mild to moderate and considerable pancreatitis could not be distinguished (Table V, Figure ). Mean amylase output could not distinguish significantly between patients with normal and those with equivocal findings, or between abnormal pancreatograms of various degree of severity (Table V). Mean volume secretion could differentiate significantly only between normal and Cambridge I findings and between Cambridge II and III pancreatitis, but not between equivocal and mild to moderate pancreatitis (Table V, Figure). Mean bicarbonate output could differentiate significantly between normal and abnormal duct changes of all degrees of severity (Table V, Figure).

\section{Discussion}

Irreversible morphological changes resulting from chronic pancreatitis may lead to a 
TABLE V Pancreatic function in patients with normal pancreatograms and chronic pancreatitis

\begin{tabular}{llllll}
\hline \multicolumn{2}{l}{ Cambridge classification } & $\begin{array}{l}\text { Volume } \\
(\mathrm{ml} / \mathrm{h})\end{array}$ & $\begin{array}{l}\mathrm{HCO}_{3} \\
(\mathrm{mmolh})\end{array}$ & $\begin{array}{l}\text { Amylase } \\
(\mathrm{IU} / \mathrm{h})\end{array}$ & $\begin{array}{l}\text { Lipase } \\
(\mathrm{IU} / \mathrm{h})\end{array}$ \\
\hline Normal & $(\mathrm{n}=10)$ & $417(84)$ & $42(10)$ & $8183(2088)$ & $176079(44431)$ \\
Cambridge I & $(\mathrm{n}=10)$ & $345(93)^{\star}$ & $34(12)^{\star}$ & $6011(4670)$ & $64024(24781)^{\star}$ \\
Cambridge II & $(\mathrm{n}=12)$ & $293(91)$ & $24(17)^{\star}$ & $3662(3615)$ & $39559(20765)^{\star}$ \\
Cambridge III & $(\mathrm{n}=16)$ & $160(69)^{\star}$ & $11(5)^{\star}$ & $2332(2334)$ & $34705(19253)$
\end{tabular}

${ }^{\star} \mathrm{p}<0.05$ when compared with previous grade of severity. Data shown as mean (SEM).

permanent loss of endocrine and exocrine function. ${ }^{1}$ In a case of suspected chronic pancreatic disease with recurrent epigastric pain, weight loss or steatorrhea, or both, ultrasound, computed tomography, secretin-caerulein test, and endoscopic retrograde cholangiopancreatography are current diagnostic procedures. ${ }^{12}$ The correlation between pancreatic function and morphological changes has been investigated in a number of studies. ${ }^{3-12}{ }^{17-19}$ Most previous analyses, however, comparing pancreatic function and ERP used different and non-standardised criteria or variations of a classification described by Kasugai without ultrasound and computed tomography as complementary imaging methods. ${ }^{3-1220}$ The Cambridge classification of chronic pancreatitis is now widely accepted as a standard grading system. ${ }^{2122}$ To date, only a single previous study correlating exocrine function of pancreas and morphological changes using the Cambridge classification including ERP, ultrasound, and computed tomography has been done. ${ }^{17}$ The aim of the present analysis was to prospectively compare pancreatic exocrine function and morphology by currently available techniques such as ultrasound, computed tomography, and ERP using the same Cambridge classification.

Most previous studies attempted to differentiate only normal from abnormal pancreas using ultrasound or computed tomography, or both, without regard for the severity of chronic pancreatitis. ${ }^{23} 32$ The sensitivity of ultrasound in chronic pancreatitis was found to be $52-90 \%$ and the specificity $90-100 \% .1323283132$ Meta analysis of 700 patients with chronic pancreatitis confirmed a sensitivity of $67 \%$ for ultrasound..$^{33}$ At $74-84 \%$ and up to $98 \%$, respectively, the sensitivity and specificity of computed tomography are somewhat better than for ultrasound. ${ }^{232428} 32$ Evaluation of the data of 592 patients with chronic pancreatitis showed a sensitivity of $74 \%$ and a specificity of $85 \%$ for computed tomography. ${ }^{33}$ Our results show that, compared with ERP, computed tomography and ultrasound may overestimate normal pancreatic morphology in $40-50 \%$ of patients by showing equivocal changes not found by ERP. Moreover, computed tomography and ultrasound can underestimate morphological changes in 50\% of patients with Cambridge I ductal findings on pancreatograms. The main reason for this over or underestimation of pancreatic morphology is the fact that accurate interpretation of focal reductions in parenchymal echogenicity or an irregular contour of the gland by ultrasound or computed tomography is difficult. The recent data of Malfertheiner et al suggest also that computed tomography is not suitable in the search for early stages of chronic pancreatitis. ${ }^{17}$ In accordance with the results of the study of Malfertheiner et al, in our patient group too, computed tomography and ultrasound provided better results with more pronounced abnormal morphological changes, as in the case of Cambridge II findings identified by ERP. ${ }^{17}$ Chronic pancreatitis with considerable Cambridge III changes could readily be diagnosed in our patients by computed tomography and ultrasound in almost all cases. Similar results have shown a severity dependent diagnostic accuracy of endoscopic ultrasonography. ${ }^{34}$ On the basis of our results, transabdominal sonography - which is a heavily operator dependent modality - used as a diagnostic tool in chronic pancreatitis may be an inexpensive and easy to perform alternative to computed tomography that may provide results of similar reliability.

Meta analysis of patients with chronic pancreatitis investigated by ERP showed a sensitivity and specificity of $86 \%$ and $90 \%$, respectively, for this technique. ${ }^{33}$ Our data have confirmed that, compared with ERP, ultrasound and computed tomography are less sensitive methods, especially in the case of equivocal and mild to moderate morphological changes. Previous studies suggested that pancreatic functional impairment may be present in the case of normal pancreatograms, and that a normal pancreatic duct on ERP does not exclude exocrine pancreatic insufficiency. ${ }^{341017-1935}$ In a study entailing a large number of patients, almost all of a subgroup of patients with normal pancreatic duct morphology and functional impairment were found to have only slight pancreatic insufficiency. ${ }^{19}$ In our patients, normal pancreatograms always correlated with normal exocrine function. In contrast, morphological duct changes were always associated with impaired pancreatic function, and the extent of pancreatic insufficiency depended on the severity of the morphological changes. Some previous studies, however, have also shown that pancreatic function may be normal in patients with pancreatic duct changes on ERP. ${ }^{18} 1936$ In a large subgroup of patients with normal pancreatic function and abnormal duct changes on ERP, almost all pancreatograms showed only equivocal findings. ${ }^{19}$ Factors such as the use of different equipment, quality of radiographs, experience in interpreting the images, in homogeneous patient groups, the type of function test used, different definitions of normal pancreatic function and grades of functional impairment may explain in part the discrepancies between previous results and our findings.

Pancreatic function tests are of benefit if grading of exocrine pancreatic insufficiency is necessary to identify a need for enzyme substitution treatment. A comparison of ERP with functional and histological changes in chronic pancreatitis showed better correlations between the secretin-caerulein test and histological changes than between ERP and histology. ${ }^{12}$ Moreover, recent findings suggest that the secretin test may identify patients with 
chronic pancreatitis earlier than ERP. ${ }^{37}$ In our patients, a normal pancreatogram excluded clinically relevant functional impairment of the pancreas. In the case of Cambridge I and II changes on ERP, pancreatic function tests, and pancreatograms proved to be complementary for establishing an accurate grading of exocrine insufficiency. In all these cases, either a dissociated or global exocrine dysfunction of varying severity was present. Additionally, our results emphasise a close correlation between ERP findings with considerable Cambridge III ductal changes and pancreatic function, as all patients without exception were shown to have global exocrine insufficiency. A significant correlation between duct morphology and degree of functional impairment, as found in our study, has previously been shown using other scoring systems. ${ }^{1718}$ In our patient group, only lipase output was found to distinguish between normal and abnormal duct morphology in all cases. Mean volume secretion, bicarbonate, and amylase outputs were all within the normal ranges in patients with equivocal duct findings. In accordance with previous results, the parameter most reliably correlating with normal and abnormal ductal findings at all grades of severity was the mean bicarbonate output. ${ }^{6} 1718$

In conclusion, our data show that using the Cambridge classification, a close correlation between ERP findings and pancreatic function can be shown. In comparison with ERP, computed tomography and ultrasound are less reliable in distinguishing between normal gland and equivocal or mild to moderate morphological changes in chronic pancreatitis. Considerable morphological changes, however, can be shown equally as sensitively as with ERP. In the case of a normal pancreatogram or when considerable changes in ultrasound, computed tomography, and ERP images are found, a close correlation exists between pancreatic function and morphology, which possibly makes the need for complementary function testing unnecessary.

Preliminary results of this study were presented at the XXIVth meeting of the European Pancreatic Club, October 1992 in Ulm, Germany.

1 Ammann R. Diagnose und Therapie der alkoholischen chronischen Pankreatitis. Eine kritische Standortbestimmung. Schweiz Med Wochenschr 1985; 115 (suppl 19): 42-51.

2 Lankisch PG, Staritz M, Freise J. Sicherheit bei der Diagnostik der chronischen Pankreatitis. $Z$ Gastroentero Diagnostik der ch.

3 Nakano S, Horiguchi Y, Takeda T, Suzuki T, Nakajima S. Comparative diagnostic value of endoscopic pancreatography and pancreatic function tests. Scand $f$ Gastroenterol 1974; 9: 383-90.

4 Dobrilla G, Fratton A, Valentini M, Vantini I, Cavallini G, Angelini G, et al. Endoscopic retrograde pancreatography and secretin-pancreazymin test in diagnosis of chronic pancreatitis: a comparative evaluation. Endoscopy 1976; 8: 118-23.

5 Ashton MG, Axon TR, Lintott DJ. Lundh test and ERCP in pancreatic disease. Gut 1978; 19: 910-5.

6 Rolny P, Lukes PJ, Gamklou R, Jagenburg R, Nilsen R. A comparative evaluation of endoscopic retrograde pancreatography and secretin-CCK test in the diagnosis of pancreatic disease. Scand $\mathcal{f}$ Gastroenterol 1978; 13: 777-81

7 Valentini M, Cavallini G, Vantini I, Farini R, Oselladore D, Fratton A, et al. A comparative evaluation of endoscopic retrograde cholangiopancreatography and the secretincholecystokinin test in the diagnosis of chronic pancreatitis: a multicenter study in 124 patients. Endoscopy 1981; 13: 64-7.
8 Elsborg L, Bruusgaard A, Strandgaard L, Reinicke V. Endoscopic retrograde pancreatography and the exocrine Gastroenterol 1981; 16: 941-4.

9 Jensen AR, Matzen P, Malchow-Möller A, Christoffersen I and The Copenhagen Pancreatitis Study Group: pattern of pain, duct morphology, and pancreatic function in chronic pain, duct morphology, and pancreatic function in chro

pancreatitis. Scand f Gastroenterol 1984; 19: 334-8.
10 Girdwood AH, Hatfield AR, Bornman PC, Denyer ME Kottler RE, Marks IN. Structure and function in noncalcific pancreatitis. Dig Dis Sci 1984; 29: 721-6.

11 Mee AS, Girdwood AH, Walker E, Gilinsky NH, Kottler RE, Marks IN. Comparison of the oral (PABA) pancreatic function test, the secretin-pancreozymin test and endoscopic retrograde pancreatography in chronic alcohol induced pancreatitis. Gut 1985; 26: 1257-62.

12 Heij HA, Obertop $H$, van Blankenstein $M$, Nix GA, Westbroek DL. Comparison of endoscopic retrograde pancreatography with functional and histologic changes in chronic pancreatitis. Acta Radiol 1987; 28: 289-93.

13 Jones SN, Lees WR, Frost RA. Diagnosis and grading of chronic pancreatitis by morphological criteria derived by ultrasound and pancreatography. Clin Radiol 1988; 39: 43-8.

14 Severinghaus JW. Electrodes for blood and gas pCO2, pO2 and blood pH. Acta Anaesthesiol Scand 1962; suppl 2: 206.

15 Gerber M, Naujoks K, Lenz H, Wulff K. A monoclonalantibody that specifically inhibits human salivary alpha-amylase. Clin Chem 1987; 33: 1158.

16 Lott JA, Patel ST, Sawhnay AK, Kazmierczak SC, Love JE. Assays of serum lipase:analytical and clinical considerations. Clin Chem 1986; 32: 1290.

17 Malfertheiner $P$, Büchler $M$, Stanescu A, Ditschuneit $H$ Exocrine pancreatic function in correlation to ductal and parenchymal morphology in chronic pancreatitis. Hepatol parenchymal morphology in ch

18 Braganza JM, Hunt LP, Warwick F. Relationship between pancreatic exocrine function and ductal morphology in chronic pancreatitis. Gastroenterology 1982; 82: 1341-7.

19 Otte M. Pankreasfunktionsdiagnostik. Internist 1979; 20 331-40.

20 Kasugai T, Juno N, Kizu M. Manometric endoscopic retrograde pancreatocholangiography:technique, significance and evaluation. Am $\mathcal{F}$ Dig Dis 1974; 19: 485-502.

21 Sarner M, Cotton PB. Classification of pancreatitis. Gut 1984; 25: 756-9.

22 Axon ATR, Classen M, Cotton PB, Cremer M, Freeny PC Lees WR. Pancreatography in chronic pancreatitis: interLees WR. Pancreatography in chronic pancreat

23 Swobodnik W, Meyere W, Brecht-Kraus D, Weschler JG Geiger S, Malfertheiner P, et al. Ultrasound, computed tomography and endoscopic retrograde cholangiopancreatography in the morphologic diagnosis of pancreatic disease. Klin Wochenschr 1983; 61: 291-6.

24 Triller J, Kappeler M, Coray T, Halter F. CT und ERCP als Kombinationsuntersuchung bei Erkrankungen des Pankreas. Fortschr Röntgenstr 1984; 141: 483-90.

25 Anacker H, Lamarque JL, Pistolesi GF. Efficiency of different radiodiagnostic techniques in pancreatic disorders. Eur $\mathcal{F}$ Radiol 1981; 1: 79-84.

26 Foley WD, Stewart ET, Lawson TL, Geenan J, Longuidice J, Maher L, et al. Computed tomography, ultrasonography and endoscopic retrograde cholangiosonography and endoscopic retrograde cholangiopancreatography in the diagnosis of pancreatic disease - A

27 Gmelin E, Weiss HD, Fuchs HD, Reiser M. Vergleich der diagnostischen Treffsicherheit von Ultraschall, Computertomographie und ERCP bei der chronischen Pankreatitis und beim Pankreaskarzinom. Fortschr Röntgenstr 1981; 134: 136-41.

28 Lackner K, Frommhold H, Grauthoff H, Mödder U, Heuse L, Braun G, et al. Wertigkeit der Computertomographie und der Sonographie innerhalb der Pankreasdiagnostik. Fortschr Röntgenstr 1980; 132: 509-13.

29 Lawson TL. Sensitivity of pancreatic ultrasonography in the detection of pancreatic disease. Radiology 1978; 128: 733-6.

30 Alpern MB, Sandler MA, Kellman GM, Madrazo B1. Chronic pancreatitis - ultrasonic features. Radiology 1985 155: 215-9.

31 Cotton PB, Lees WR, Vallon AG, Cottone M, Croker JR Chapman M. Grayscale ultrasonography and endoscopic pancreatography in pancreatic diagnosis. Radiology 1980 134: 453-9.

32 Fiegler W, Wegener $H$, Hartmann $K$, Felix $R$. Computertomographie und Sonographie: Vergleichsstudie bei Erkrankungen des Oberbauches und des Retroperitoneums. Fortschr Röntgenstr 1980; 123: 262-7.

33 Glaser J. Bildgebende Diagnostik bei Erkrankungen der Bauchspeicheldrüse. Dtsch Med Wochenschr 1990; 115: 1361-7.

34 Nattermann C, Goldschmidt AJW, Dancygier $H$ Endosonographie bei chronischer Pankreatitis. Ultraschall Med 1992;13: 263-70.

35 Elsborg L. Endoscopic retrograde pancreatography and exocrine pancreatic function. Digestion 1987; 37 (suppl 1): 18-24.

36 Angelini G, Pederzoli P, Caliari S, Fratton S, Brocco G Marzoli G, et al. Long-term outcome of acute necrohem orrhagic pancreatitis. Digestion 1984; 30: 131-7.

37 Lambiase L, Forsmark CE, Albert C, Toskes PP. Secretin test diagnosis chronic pancreatitis earlier than ERCP. Gastroenterology 1993; 104: A315. 